\title{
Decision-making Study on Multi-objective Business Process Improvement of the Service-oriented Manufacturing System
}

\author{
Qi Tang, Guozhi Lin* and Guoqiu Wu \\ Management School, Liaoning Key Laboratory of Equipment Manufacturing \\ Management Engineering, Shenyang University of Technology \\ tangqi20050708@163.com
}

\begin{abstract}
Considering the transformation of Service-oriented manufacturing, this paper clarifies the requirements of the service-oriented manufacturing business process and explores the basic idea with competitive strategic guidance and competitive advantage expectation. For meeting the customer requiring objectives and operational requiring objectives, we proposed the mathematical model and Logical model to measure the improvement degree of business process and the method to analyze and diagnose the key improvement points and important improvement aspects. This paper enriches and extends the theories and methods of business process improvement, and can provide method support in practice.
\end{abstract}

Keywords: Service-oriented manufacturing; Business process improvement; Mathematical model; Logical model

\section{Introduction}

The expansion of manufacturing enterprises from the manufacturing sector to the field of service conforms to the law of development of consumer demand and the law of evolution of the industrial society to backward industrial society[1] .It is also the inevitable result of the division of manufacturing industry chain, integration and differentiation of competition[2-3]. Most of the manufacturing system in the developed countries experienced a long evolution process, which from pure product manufacturing to expand to the service area [4]. And manufacturing enterprises have changed from the product manufacturers to service providers, to carry out the manufacture of services and service oriented manufacturing [5-6]. Service-oriented manufacturing need achieve customer and operational requirements as objectives to maximize the value of customers [7-8]. Service-oriented manufacturing mainly include "service-based product" and "commercialized service" two route forms which combine front with back end business[910] to achieve the best combination of all business processes[11-12].

Considering the expansion of manufacturing enterprises from the manufacturing field to the service field, this paper clarifies the characteristics of the service-oriented manufacturing business process, and explores the basic ideas, logical steps and quantitative analysis methods of business process improvement, which provides theory and technology support to better completion of the service transformation and business process improvement.

\section{Characteristics and Structure of Service-oriented Manufacturing System}

\subsection{Characteristics}

(1) Enhance service functions

The service-oriented manufacturing business process is no longer simple productive manufacture, but to expand towards the services of the front pre-stage development and 
back post-stage maintenance etc [13]. It melts the productive manufacture with the prestage development, post-stage maintenance and instant services, enhances the proportion of the service business and strengthens then service functions 14-15], thus to make customers sufficiently obtain various benefits from products and services.

(2) Customers participate in the whole business process

In the service-oriented manufacture, a customer is no longer the passive product receiver, but the enterprise's "co-producer". Customers not only participate in the design and production of products and services, but also c-accomplish the improvement and innovation of products and services. They initiatively participate in the enterprise's business process optimization in order to reach the win-win and co-create value with enterprises.

(3) Flexible business process

The business process of the service-oriented manufacture could expand towards, respectively or both, its front and back from the productive phase to provide the valueadded services based on products; or manufacturers could rely on their productive service advantages [16-17], and quit or outsource part of their non-value-added business relating to production in order to transform into enterprises mainly providing professional services. The business process as a whole could be accomplished by a certain manufacturer, or co-accomplished by an enterprise alliance based on strategic cooperation.

(4) Services become vital for value increment

The whole value chain of service-oriented manufacturing business process can be divided into two types: one is "smiling curve" and the other one is "ingot curve" as shown in Figure 1 and Figure2 respectively. In the whole value chain of "smiling curve", the middle part refers to the processing and manufacturing business with low additional value and both end parts refer to the productive service business with high additional value such as development and design, brand marketing as well as after-sales service, which reflects that the link with high additional value transforms from manufacturing to the service on both ends [18]. The service-oriented manufacturing can help the enterprises to get rid of or relieve their passive situation of product homogeneity, excessive competition and small profits. In the whole value chain of "ingot curve", the processing and manufacturing in the middle part becomes the key link of value creation and both ends still refer to the productive service business with high additional value, which reflects that the contribution of processing and manufacturing to the value creation of some enterprises is more outstanding and significant since such enterprises have leading technology and monopoly advantage which professional manufacturing and scale-production-dominated, although the development and brand are still important for their value creation. 
$R \& D$ and design

marketing and service

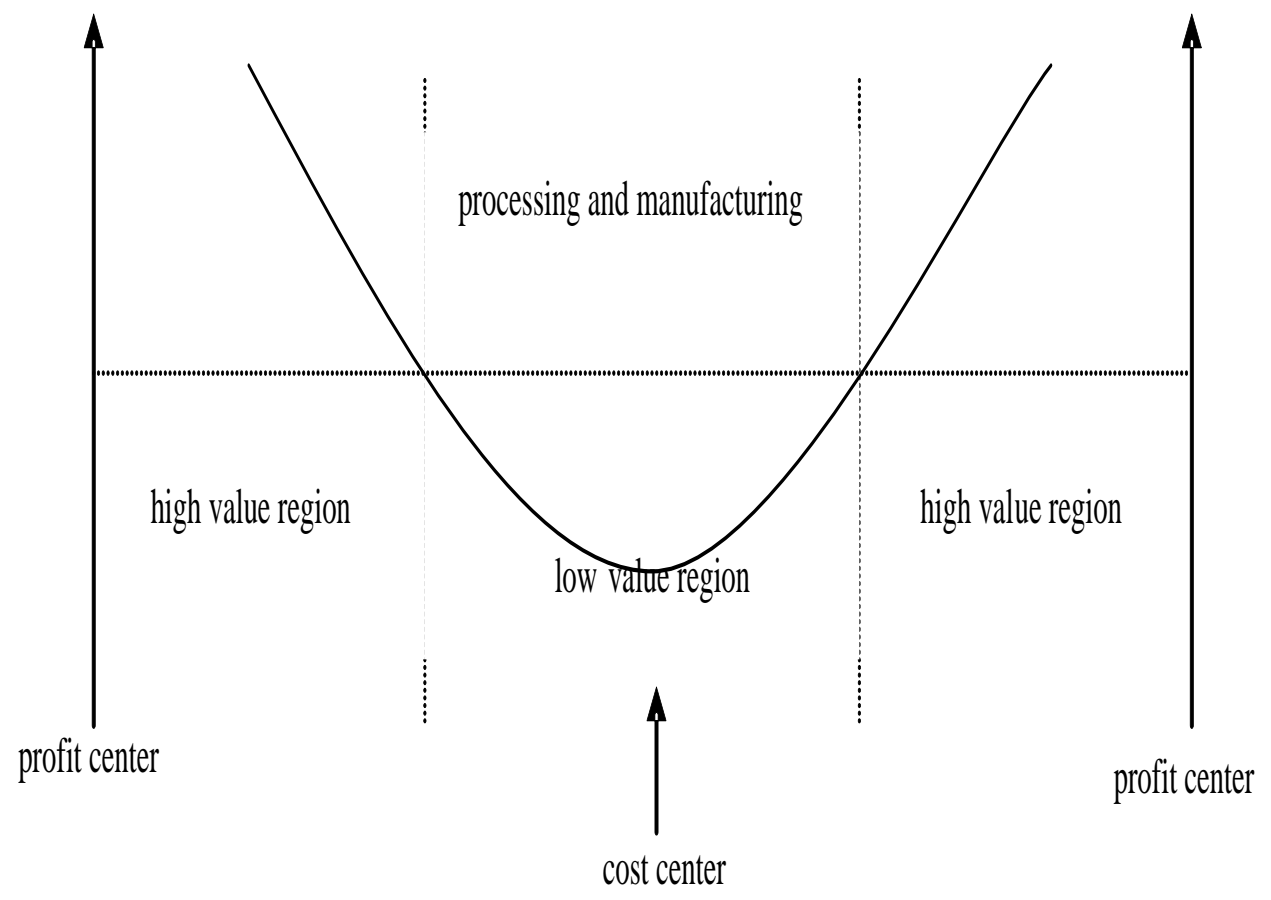

Figure 1. Smiling Curve of the Whole Value chain in Manufacturing System

$R \& D$ and design

marketing and service

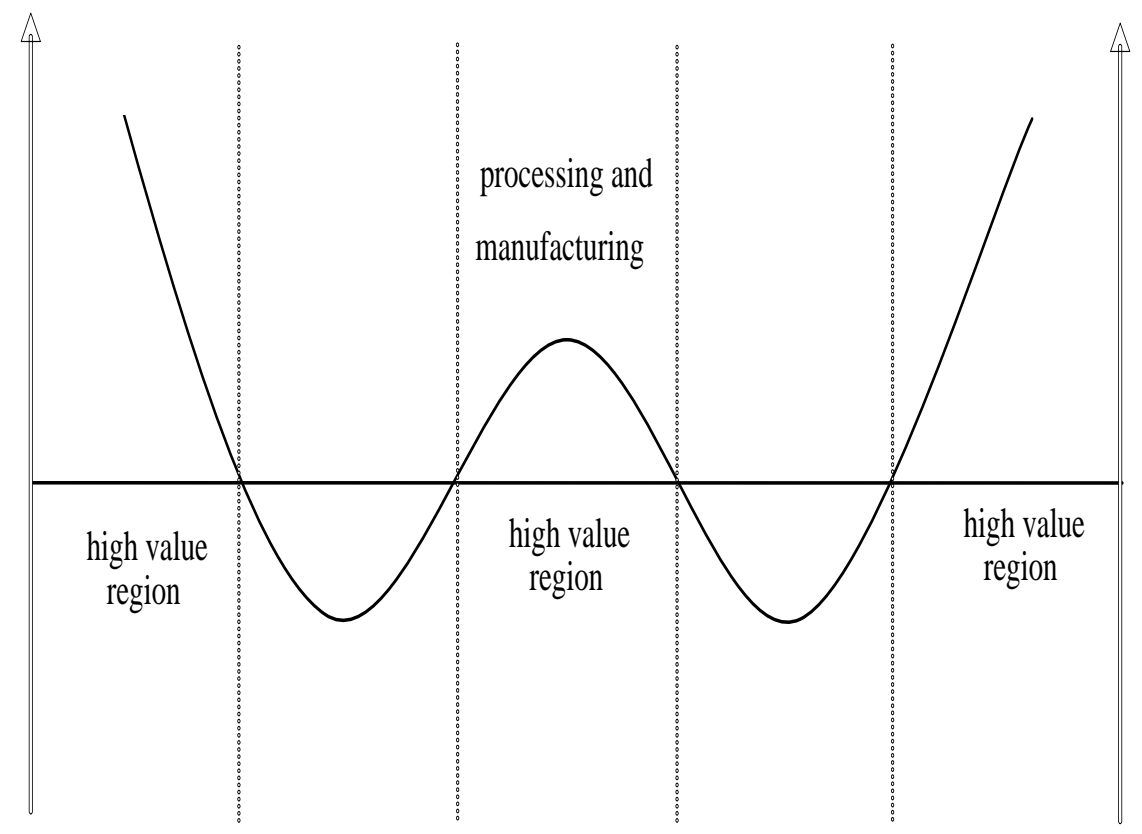

Figure 2. Wing Curve of the Whole Value Chain in Manufacturing System 


\subsection{Basic Structure of Service-oriented Manufacturing Business Process}

The service-oriented manufacturing business process contains four cornerstones: prestage development, manufacture, post-stage maintenance, and instant service. The basic contents that each cornerstone contains are as shown in Figure 3. In practice, the serviceoriented manufacturing business process finds expression in several basic composing forms: (1) combining manufacture with the front R\&D and design; (2) combining the manufacture with the back after-sale service; (3) combining the manufacture with the both front and back productive service links.

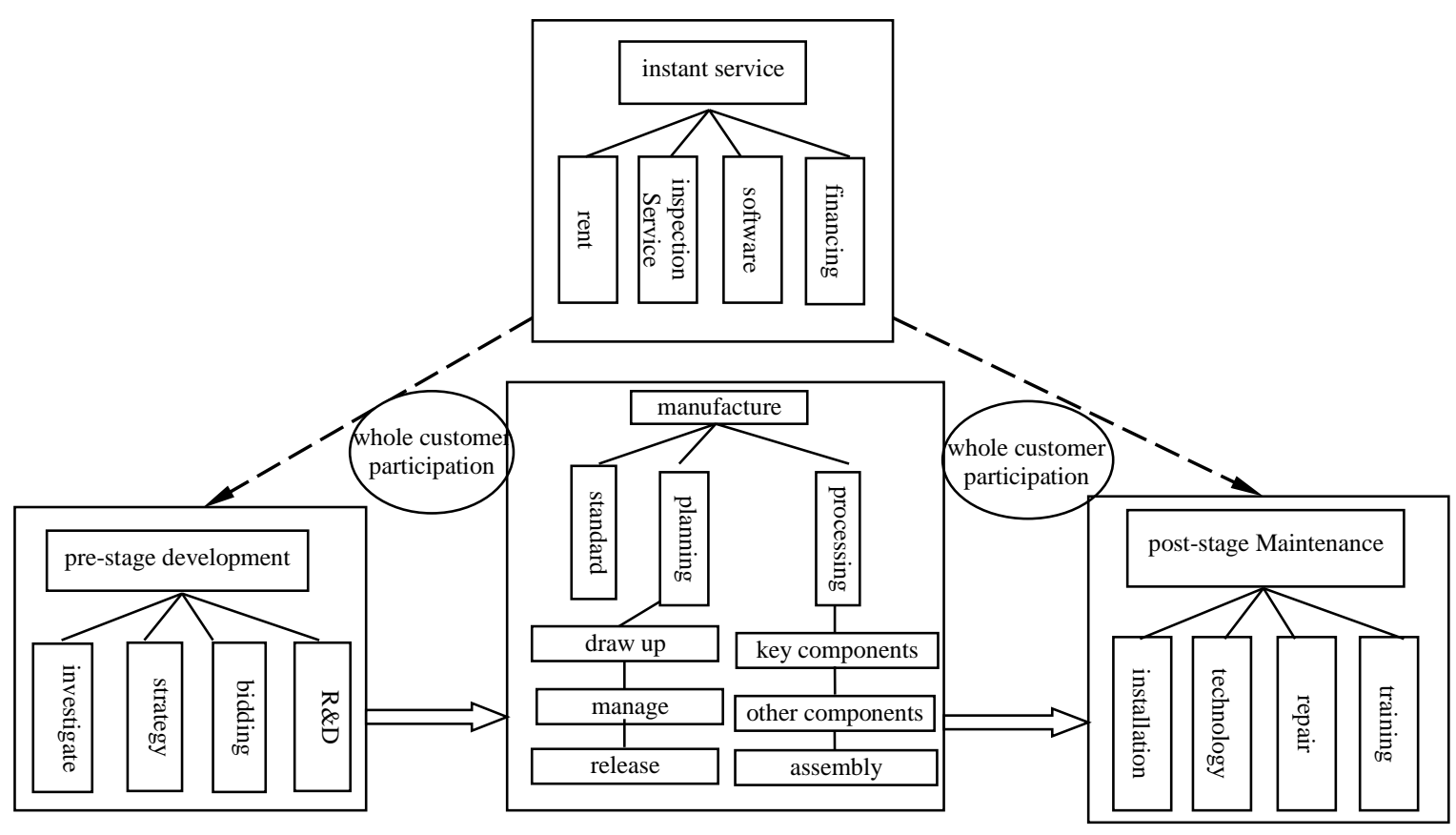

Figure 3. Basic Structure of Service-oriented Manufacturing Business Process

\section{Requiring Objectives of Business Process Improvement for Service- Oriented Manufacture}

The improvement of the service-oriented manufacturing business process containers two layers of customer and operational requiring objectives: the first is to maximally satisfy the customer requirements; and the second is to properly satisfy the operational requiring objectives. Satisfying the customer requirements contain the qualification elements and winning elements of the products and services required by customers. The qualification elements are the basic requirements for the products and services firmly standing in the market; and the winning elements are the comparative advantages in performances, characteristics, or compounding of the products and services. Satisfying operational requiring objectives refer that the whole business process shall not only be capable to provide customers the required products and services with the economical and reliable form, but also be capable to guarantee the realization of winning elements and the competitiveness of the products and services. The former capability is aimed at improving the customer satisfaction and acquiring the maximum added value. And the later capability is aimed at improving the core competitiveness of the business process and guaranteeing the output products and services have advantages for winning customers. Therefore, the improvement of service-oriented manufacturing business process should start off with satisfying the customer and operational requiring objectives, and take the 
requirements of each business process link which satisfy the two kinds of objectives as the cut-in points for optimizing the business process.

\section{Mathematical and Logic Models of Service-oriented Manufacturing Business Process Improvement}

\subsection{Mathematical Model}

Assuming that there are $\mathrm{n}$ customer requiring objectives and $\mathrm{m}$ links of the entire business process, and the comprehensive importance achieving the $i$ th customer requiring objective is $w^{p}{ }_{i}(i=1, \ldots, n)$. The calculation of $w^{p}{ }_{i}$ should not only consider the importance $w_{i}$ of the ith customer requiring achieving the $i$ th customer requiring objective. In formula (1),it is the product of both ${ }^{[19-20]}$, which can be written as objective with respect to the other requiring objectives, but also consider the difficulty degree $p_{i}$

$$
w_{i}^{p}=w_{i} p_{i}
$$

$w_{i}=\Delta w_{i}+w_{i}^{o} \cdot w_{i}^{o}$ is the indicator weight of the $i$ th requiring objective, $\Delta w_{i}$ is the new increased weight when competition advantage is from the element. $p_{i}$ can be measured by the ratio between the objective satisfaction and the current satisfaction of the $i$ th requiring objective. Assuming that $p_{i}^{t}$ is the objective satisfaction degree after improvement or given competition advantage intensity, and $p^{s}{ }_{i}$ is the current satisfaction. In the formula (2), $p_{i}$ can be written as:

$$
p_{i}=p_{i}^{t} / p^{s}
$$

$\alpha_{j}$ is the product of $u_{j}$ and $l_{j}$, which can be written as:

$$
\alpha_{j}=u_{j} l_{j}
$$

The improvement rate $l_{j}$ of the business process link reflects the relationship between the improvement objective and the status. Therefore, the calculation of $l_{j}$ should not only consider the improvement rate $c_{j}$ of the flow quantity of the jth business process link, but also should consider the influence degree $e_{j}$ of various associated business process links of the $j$ th link comparing with $c_{j}$. Assuming $h_{j}$ is the relevancy degree between the $j$ th business process link and the other business process links, then $e_{j}=h_{j} c_{j}$. In the formula (4) $l_{j}$ should be the sum of $c_{j}$ and $e_{j}$, which can be written as:

$$
l_{j}=c_{j}+e_{j}=c_{j}\left(1+h_{j}\right)
$$

$h_{j}$ can be calculated by the analytic hierarchy process according to the correlated coefficients between the business process links. Since the improvement rate of flow quantity can be measured by the quotient between the objective flow quantity (namely, the expected maximum flow quantity) and the actual flow quantity, $c_{j}$ in formula (5) can be written as:

$$
c_{j}=X_{j} / x_{j}, \quad 0<x_{j} \leq X_{j}
$$

$X_{j}$ is the maximum flow quantity, and $x_{j}$ is the actual flow quantity. The larger $c_{j}$ is, the larger the improvement degree will be. When $x_{j}=0$ or $x_{j}>X_{j}$, the $j$ th business process link needs to be comprehensively improved. When $x_{1}=X_{1}, \cdots, x_{m}=X_{m}$ and 
$X_{1}=X_{2}=\cdots X_{m}$, the flow quantity of each business process link has reached the maximum or ideal state of coordination.

Based on the formula (1), (2), (3), (4) and (5), it can get the improvement degree of each business process link for the customer requiring objectives:

$$
\alpha_{j}=\sum_{i=1}^{n} a_{i j} w_{i}\left(1+h_{j}\right)\left(p_{i}^{t} / p_{i}^{s}\right)\left(X_{j} / x_{j}\right), \quad j=1, \cdots, m
$$

Assuming that there are $\mathrm{d}$ operational requiring objectives and $\mathrm{m}$ business process links, the comprehensive importance achieving the $i$ th operational requiring objective is $r_{i}^{q}(i=1, \ldots, d)$. The calculation of $r_{i}^{q}$ should not only consider the importance $r_{i}$ of the $i$ th operational requiring objective with respect to the other requiring objectives, but also consider the difficulty degree $q_{i}$ achieving objective satisfaction of the $i$ th operational requiring objective. In formula (7), it is the product of both, which can be written as:

$$
r_{i}^{q}=r_{i} q_{i}
$$

$q_{i}$ can be measured by the ratio between the objective ability and the current ability of the $i$ th operational requiring objective. Assuming that $q_{i}^{t}$ is the value of objective ability after improvement, and $q_{i}^{s}$ is the current value of ability. In formula (8), $q_{i}$ can be written as:

$$
q_{i}=q_{i}^{t} / q^{s}
$$

The larger $q_{i}$ is, the more difficulty it is to realize targets of the operational requiring objective. The relevancy between the $j$ th business process link and the $i$ th operational requiring objective is $b_{i j}(j=1, \ldots, m)$, and the weighted relevancy with all the operational requiring objectives is $s_{j}, s_{j}=\sum_{i=1}^{d} b_{i j}{ }^{q}{ }_{i}$. The improvement degree of the $j$ th business process link for the operational requiring objective is $\beta_{j}$, and the improvement rate is $l_{j}$. In formula (9), $\beta_{j}$ is the product of $s_{j}$ and $l_{j}$, which can be written as:

$$
\beta_{j}=s_{j} l_{j}
$$

$l_{j}$ can be calculated by formula (4) and formula (5).

Based on the formula (4), (5), (7), (8) and (9), it can get the improvement degree of each business process link for the operational demand:

$$
\beta_{j}=\sum_{i=1}^{d} b_{i j} r_{i}\left(1+h_{j}\right)\left(q_{i}^{t} / q_{i}^{s}\right)\left(X_{j} / x_{j}\right), j=1, \cdots, m
$$

\subsection{Logic Model}

According to the above improvement ideas, the improvement of the service-oriented manufacturing business process's a cycling rising process according to the requirements of customer requirements, operational requirements and competitive strategies, continuously to improve the business process to make it unremittingly approach the improvement objective. The logic model is shown in Figure 4. 


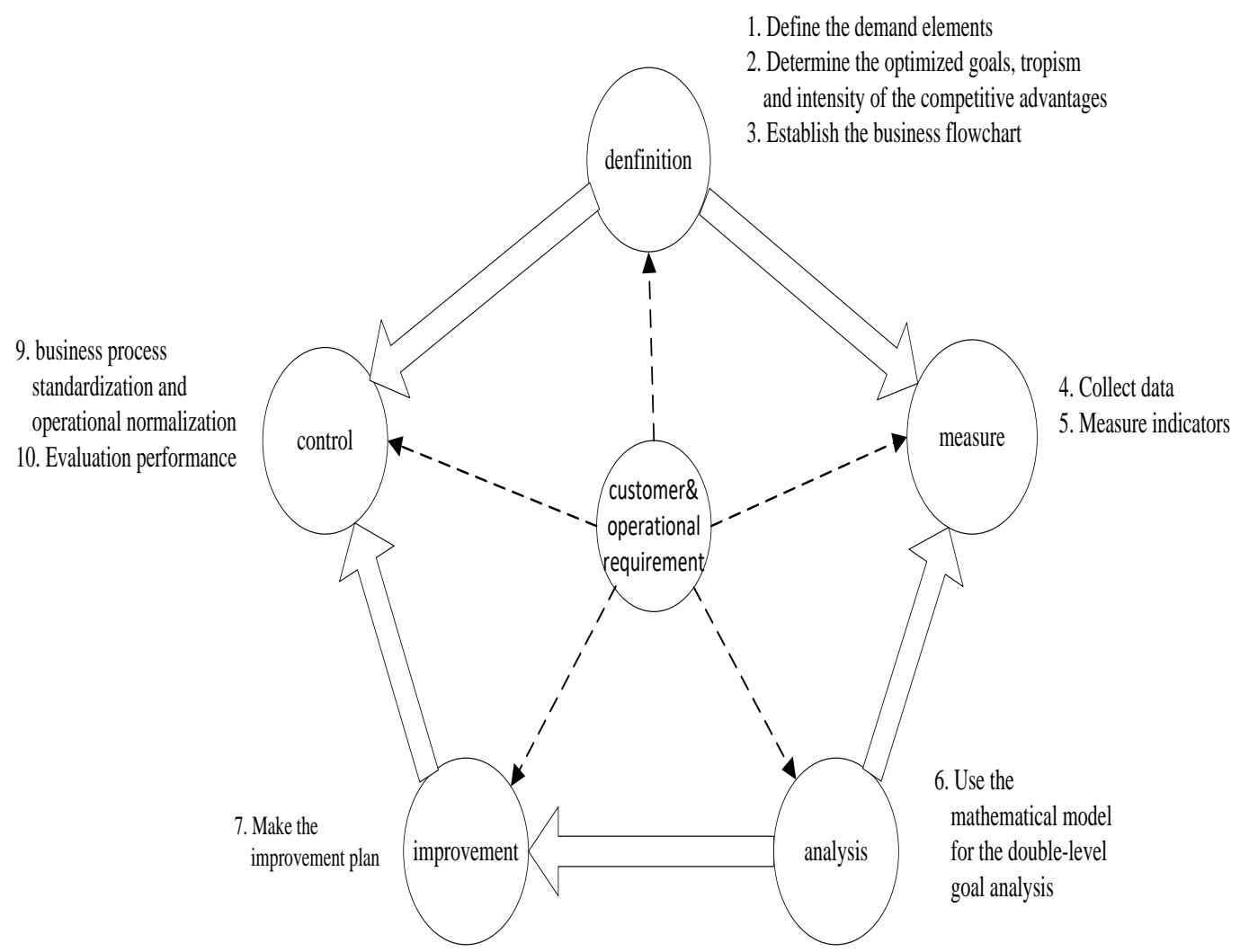
Figure 4. Logic Model of Service-oriented Manufacturing Business Process
Improvement

(1) Definition Phase

Define the elements of customer demands and operational demands. Determine the double level improvement objectives, and tropism and intensity of competitive advantages. Make clear the structure of business process, and create business flowchart.

(2) Measure phase

Establish the main measure indicators of customer requiring objectives, operational requiring objectives and advantage intensity. Collect the actual data related to markets and enterprises to measure the actual value of the measure indicators. Determine the importance of the measure indicators of customer demands and operational demands, analyze the difficulty degree achieving each requiring objective, and then form the indicator weight.

\section{(3) Analysis phase}

Bi-level objective analysis on business process is conducted to evaluate the required improvement degree and find the existing problems. The mathematical model can be used to calculate the improvement degree $\left(\alpha_{j}\right)$ of each link to meet the customer demands, improvement degree $\left(\beta_{j}\right)$ of each link to meet the operational needs and the average improvement degree $(\bar{\alpha}, \bar{\beta})$. Then diagnose the key improvement links, the improvement aspects requiring emphasis and the existing problems on this basis. The analysis and diagnosis of key improvement and important links are as shown in Figure 5. 


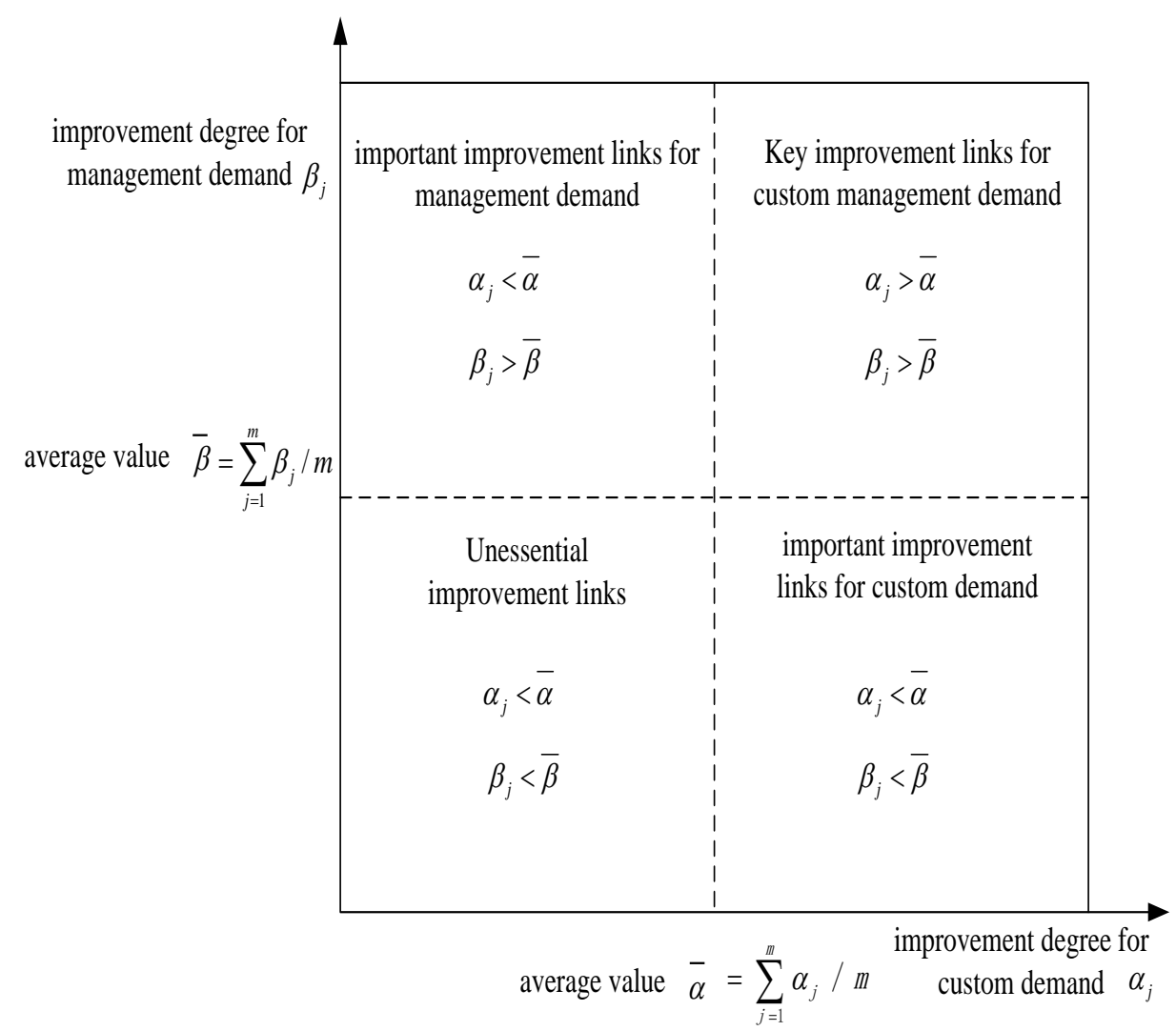

Figure 5. Analysis and Diagnosis Diagram on Key and Important Links of Business Process Improvement

(4) Improvement phase

According to the ranks of the improvement degree for each business process link, and diagnostic key improvement links, important improvement links and existing problems, organize the implementation in accordance with the primary and secondary classification.

(5) Control phase

During the process of the optimized and improved implementation, it should pay attention to the investigation of the realized degree of the requiring objectives, establish the new standards and operation norms to control the business process[19], and take the business process improvement degree as the evaluation mechanism of the business process improvement performance, in order to form a cycling mode to continuously improve and approach the improvement objectives.

\section{Case Analysis}

FX is a production-oriented manufacturing enterprises, mainly engaged in the manufacture of wind turbine assembly and part., in order to improve the technology level and service ability, it takes the way of cooperation with universities to take advantage of the technology partner of SUT University of national science and Technology Park and wind energy institute to speed up the transformation service-oriented manufacturing. After then the company began to extend from the equipment manufacturing of wind power generation to its front and end business. At present, FX company has a total of 10 business process, which not only includes the production of parts and the assembly of the whole machine, and extends forward to market research, design and planning, but also 
includes the brand marketing and after-sales maintenance and testing services, specifically shows in Figure 6.

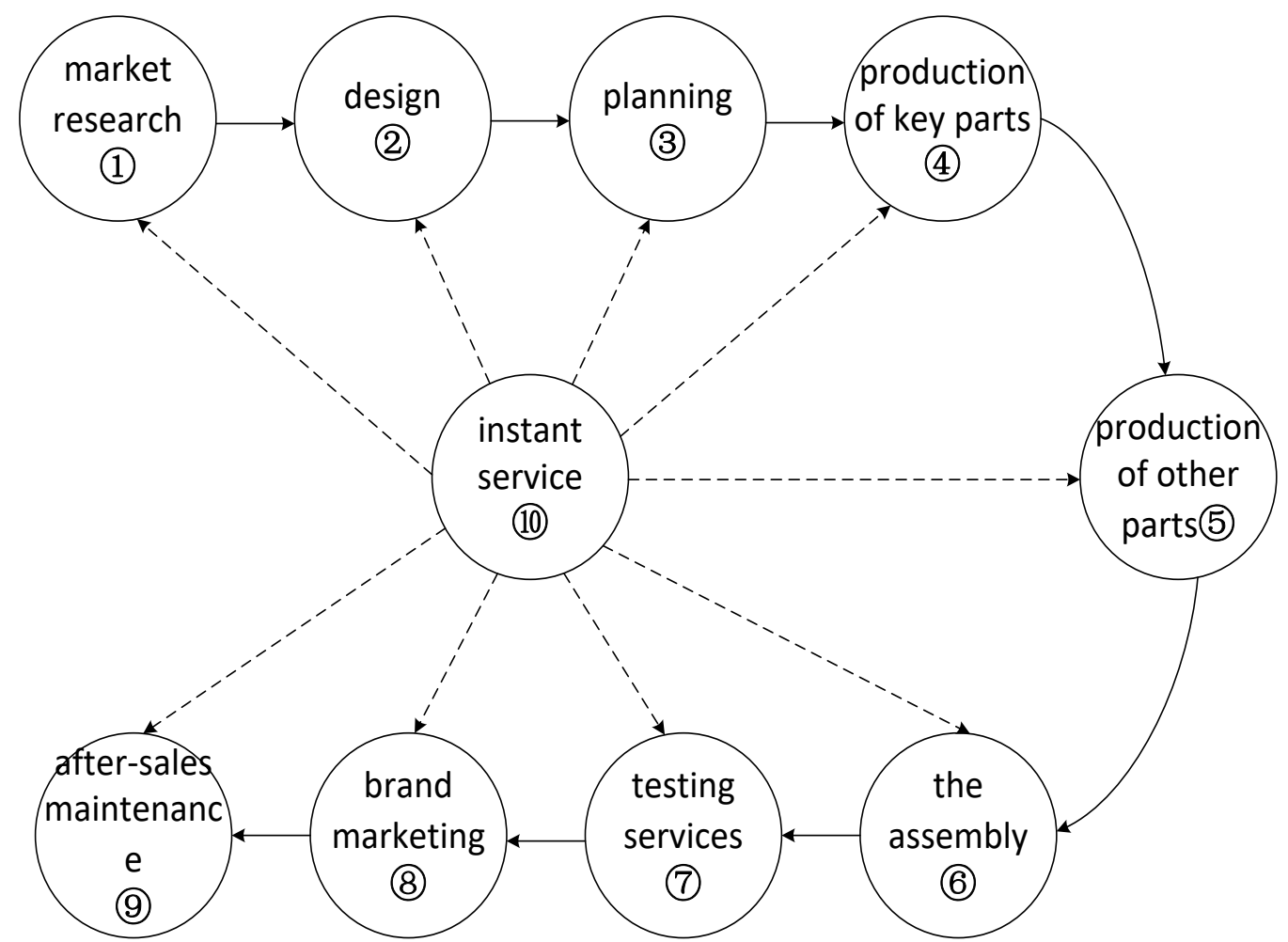

Figure 6. Business Process of FX Company

At the beginning of cooperation alliance and the service-oriented transformation the company did not use any the business process improvement methods which aimed to increase customer value, improve performance or shorten the process time and improve the efficiency alone, but to meet customer needs and operational requirements of the bilevel requirements of the target, improve the product services and business process under the guidance of competitive strategy. First, based on the survey analysis of market demands, competition and business operational, FX further clarifies the indicators of customer requiring objectives and operational requiring objectives to define specific requirements for process improvement objectives, determines the tropism and strength of the competitive advantages of the products and services to be moderate rated wind speed, utmost speed of wind turbine, lower prices and high quality of after-sale service, and decides values to the intensity of the new expected competitive advantages (the wind speed is moderate for $\pm 12 \mathrm{~m} / \mathrm{s}$, the wind turbine speed is utmost for $+35 \mathrm{r} / \mathrm{min}$, the lower price is for $-0.2 \mathrm{mil}$.CNY, and the high quality after-sale service is for $+15 \%$ satisfaction).Meanwhile FX focuses the operational security ability on strong $R \& D$, lower costs of organization operational, service capabilities and diversified marketing channels. According to the specific requirements for process improvement objectives , the tropism and strength of the competitive advantages of the products and services ,the key ability to support for operational, FX respectively makes decision to the importance degree of each indicator of customer requiring objectives and operational requiring objectives, $w_{i}$ and $r_{i}$, On this basis, make clear the actual value before improving and the objective value of each demand improvement indicator, use $p_{i}^{s}, q_{i}^{s}$ and $p_{i}^{t}, q_{i}^{t}$ to represent them. As shown in Table 1 and Table 2. It inherited the previous maximum business process improvement 
method targets to meet customer needs and create high added value. And at the same time It also stressed the importance of competitive advantage of product service and the capabilities to support for win the competitive advantage of business in business process improvement.

Secondly, draw the quality house of the customer and operational requirements, which is based on the data obtained from the preliminary investigation and consultation [20], shown in Figure 7 and Figure 8. Respectively calculate the improvement degree $\alpha_{j}$ for the customer requiring objectives and $\beta_{j}$ for the operational requiring objectives of each business process link by the above mathematical model, and $\bar{\alpha}$ and $\bar{\beta}$ for average improvement degree, shown in Table 3. The relevant data analysis tool and the improved degree quantification method are used here to overcome the lack of the corresponding analytic tools and the necessary improvement measures to improve the business process improvement method.

Table 1. Customer Requiring Indicators and Weighs

\begin{tabular}{lcccccc}
\hline $\begin{array}{l}\text { customer requiring } \\
\text { indicators }\end{array}$ & $\begin{array}{c}\text { intensity } \\
\text { values }\end{array}$ & $\Delta w_{i}$ & $w_{i}{ }^{0}$ & $w_{i}$ & $p^{t}{ }^{t}$ & $p^{s}$ \\
\hline moderate wind speed & $\pm 12 \mathrm{~m} / \mathrm{s}$ & 0.01 & 0.127 & 0.137 & 5 & 3 \\
runner bearing capacity & & & 0.087 & 0.087 & 4 & 3 \\
wind turbine speed & $+35 \mathrm{r} / \mathrm{min}$ & 0.027 & 0.145 & 0.172 & 4 & 2 \\
annual energy output & & & 0.087 & 0.087 & 5 & 2 \\
useful life & & & 0.087 & 0.087 & 4 & 3 \\
lower price & $-0.2 \mathrm{mil.CNY}$ & 0.03 & 0.135 & 0.165 & 5 & 3 \\
high quality after-sale & $+15 \%$ & 0.024 & 0.145 & 0.169 & 5 & 3 \\
service & & & 0.097 & 0.097 & 5 & 2 \\
Instant service & & & 0.091 & 0.091 & 4 & 3 \\
brand awareness & & & & & & \\
\hline
\end{tabular}

Table 2. Operational Requiring Indicators and Weighs

\begin{tabular}{lccc}
\hline operational requiring indicators & $r_{i}$ & $q_{i}^{t}$ & $q_{i}^{s}$ \\
\hline quality control system & 0.097 & 4 & 3 \\
cost of organization operation & 0.138 & 5 & 3 \\
flexibility of production system & 0.097 & 5 & 2 \\
green character of production system & 0.095 & 5 & 3 \\
design ability & 0.153 & 5 & 2 \\
service ability & 0.16 & 5 & 2 \\
Yield rate & 0.099 & 4 & 3 \\
marketing channel & 0.16 & 4 & 2 \\
\hline
\end{tabular}




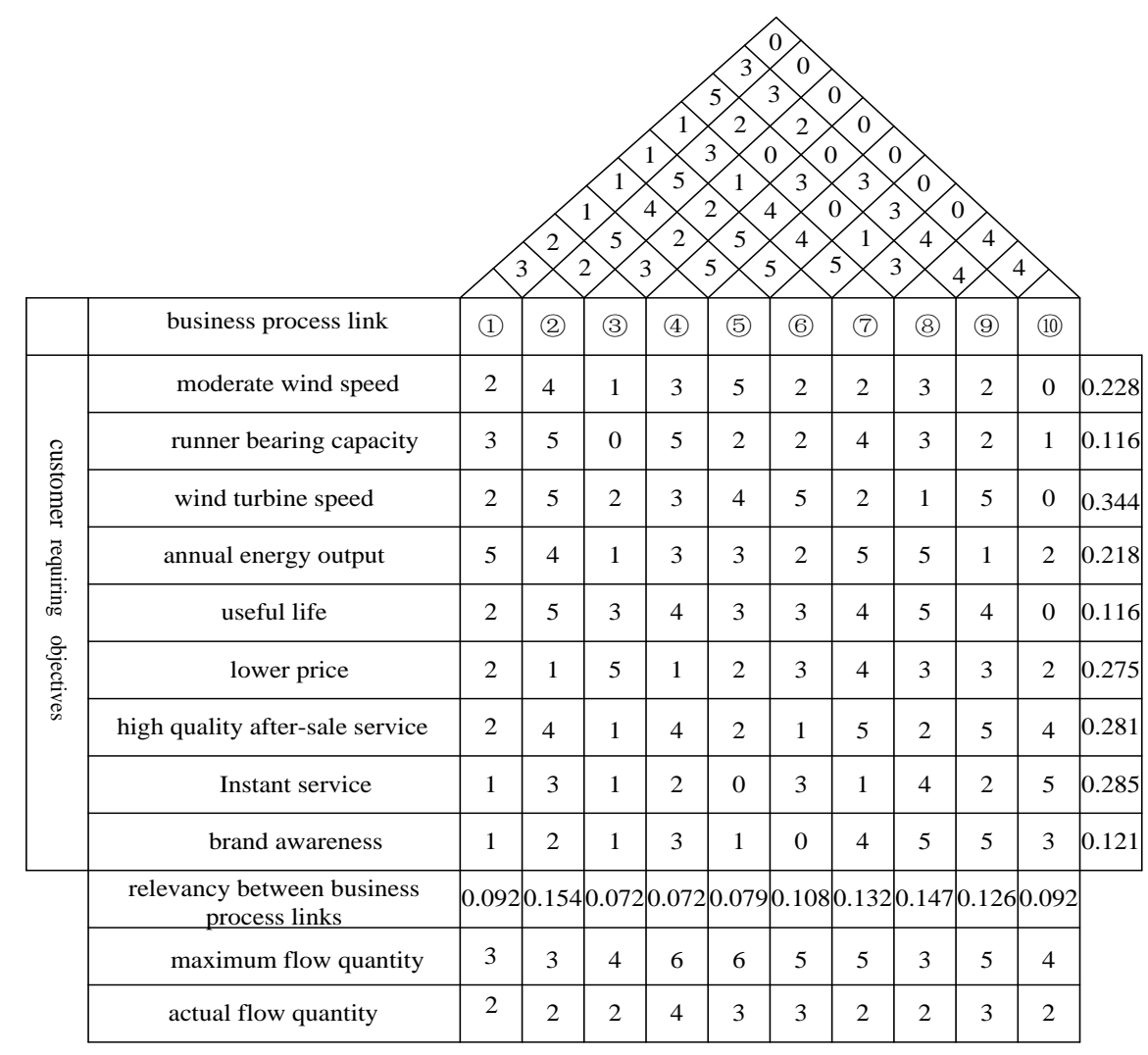

Figure 7. The Quality House of Customer Requirements

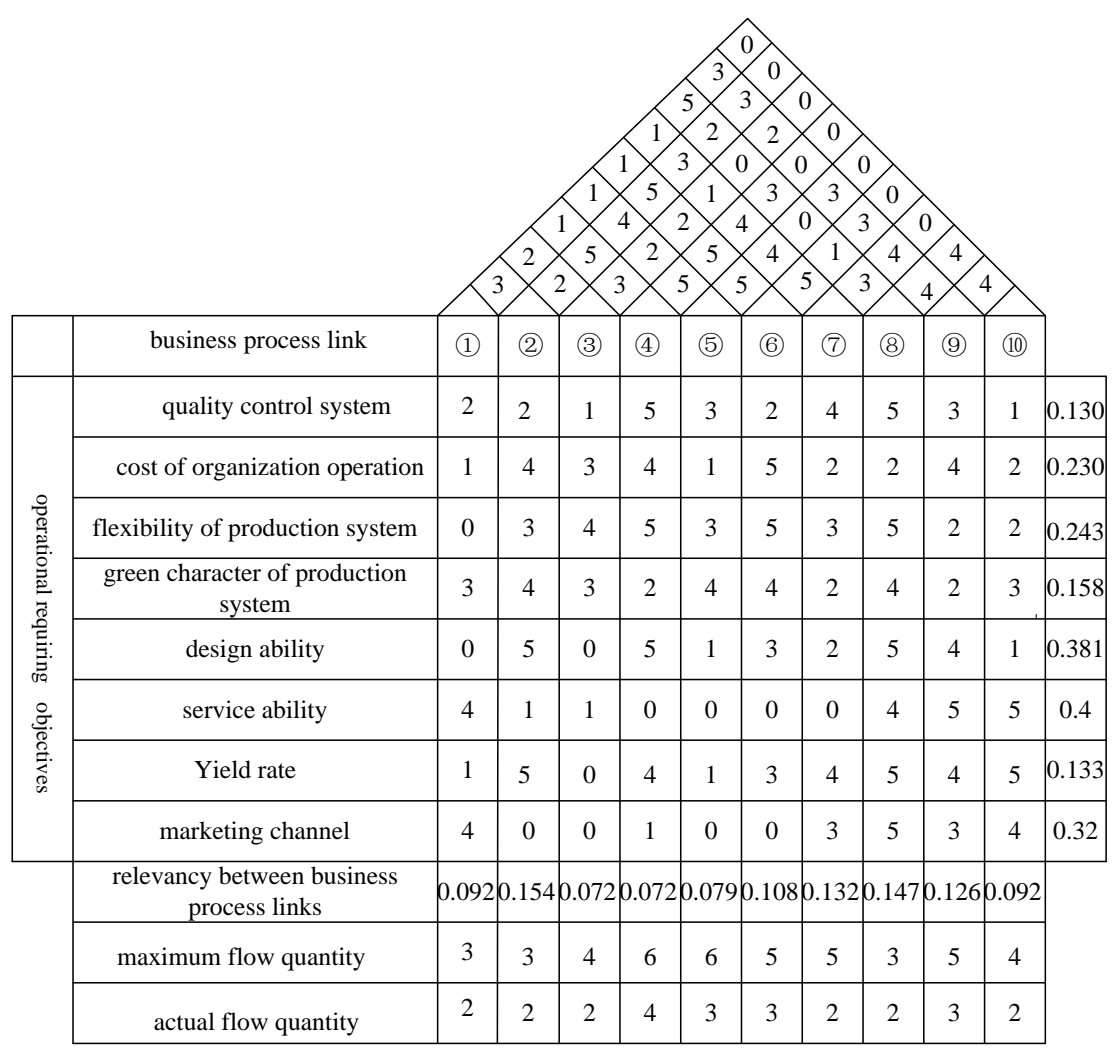

Figure 8. The Quality House of Operational Requiring Objectives 
Table 3. Improvement Degree of the Business Process

\begin{tabular}{cccccccccccc}
\hline $\begin{array}{c}\text { process } \\
\text { link }\end{array}$ & $(1)$ & 2 & $(3$ & 4 & (5) & (6) & (7) & (8) & 9 & (10 & $\begin{array}{c}\text { Aver } \\
\text {-age }\end{array}$ \\
\hline$\alpha_{j}$ & 7.10 & 12.76 & 7.60 & 9.24 & 10.76 & 9.52 & 18.22 & 11.38 & 12.42 & 8.77 & 10.78 \\
$\beta_{j}$ & 6.52 & 9.54 & 5.71 & 9.42 & 5.38 & 8.86 & 12.11 & 15.01 & 13.38 & 12.83 & 9.88 \\
\hline
\end{tabular}

Thirdly, the results of improvement degree shows that the links in which both $\alpha_{j}$ and $\beta_{j}$ are larger than the average are testing services, brand marketing, brand marketing and after-sales maintenance. They are the key links in badly need of improvement. The links in which $\alpha_{j}$ is smaller than average and $\beta_{j}$ is larger than the average is instant service. It indicates that it is the important links requiring emphasis on operational improvement. The links in which $\beta_{j}$ is smaller than average and $\alpha_{j}$ is larger than the average is design. It indicates that it is the important links requiring emphasis on customer requiring improvement. Therefore, FX makes the improvement plan on technological means, operating procedures, personnel allocation and operational system aiming at these links. The previous business process improvement methods can only identify the aspects need to improve, and here on the basis of the progress of the calculation results and analysis figure, not only can know the improvement degree of meeting customer requiring objectives and operation requiring objectives, but also diagnose the key improvement points and important improvement aspects and the problems.

Fourth, FX updates and adjusts the relevant process standards and operation regulations based on the improvement plan, implementation effect, and adjustment after improvement and new technological means of quality test. FX speeds up its transformation from productive manufacturer to service-oriented manufacturer through implementation of continuous improvement. At present, the company has increased the market share of its products and the brand influence with strong competitive advantage and strength in development and design, processing and manufacturing, as well as aftersales maintenance of medium-sized wind power generators.

\section{Conclusion}

In order to adapt to the service-oriented development trend of international manufacturing industry and the need of transformation of manufacturing enterprises into service-oriented manufacturing, this paper puts forward the basic idea of service-oriented manufacturing business process improvement with customer and operational requiring objectives, presents logical model and mathematic model of business process improvement by combination of quantitative analysis and qualitative analysis, as well as the method to analyze and diagnose the key and important improvement links, so as to overcome the limitation of previous productive manufacturing process and make up for the shortcomings and deficiencies existing in the business process improvement due to neglect of competitive strategic guidance and competitive advantage, thus to enrich and extend the theoretical methods of business process optimization and provide method support and application reference for the transformation of enterprises from manufacturing to service and the business process improvement practice.

\section{Acknowledgments}

This work is supported by National Natural Science Foundation of China under Grant (71001074); Humanity Social Science Youth foundation of Ministry of Education of China under Grant (13YJC630146); Humanity and Social Science Research Project of Education Department of Liaoning province (ZJ2015037), Liaoning Province Social Science Planning Fund Project. 


\section{References}

[1] P. Gaiardelli, B. Resta and V. Martinez, "A Classification Model for Product-service Offerings”, Journal of Cleaner Production, vol. 66, no. 3, (2014), pp. 507-519.

[2] N. N. Jing and H. H. Hu, "Quality Gaps and Knowledge Gaps in an New Product Development Process", Science Research Management, vol. 31, no. 2, (2010), pp. 127-133.

[3] L. B. Shu and C. D. Hu, "Study on Business Process-oriented Knowledge Creation for Modern Manufacturing Enterprises", Science of Science and Mmanagement of S \& T., vol. 33, no. 4, (2012), pp. 75-79.

[4] W. Ulaga and W. J. Reinartz, "Hybrid Offerings: How Manufacturing Firms Combine Goods and Services Successfully", Journal of Marketing, vol. 75, no.6, (2011), pp. 5-23.

[5] Z. He, L. Y. Sun and C. Y. Zhu, "The Concept, Problems and Foresight of Service-oriented Manufacture", Scientific Research, vol. 28, no. 1, (2010), pp. 53-60.

[6] Q. S. Zhang, "Production and Operation Management", Chemical Industry Press, Beijing, (2011).

[7] $\mathrm{H} \mathrm{Li}$ and X. J Gu, "Development model of Modern Manufacturing Services and Development Strategy in China", Mechanical Engineering in China, vol. 23, no. 17, (2012), pp. 798-809.

[8] Q. Tang, "Integrated Batching and Scheduling on Multi-variety Batch Production by Turns in Process Industries", Systems Engineering Theory \& Practice, Vol. 35, no. 4, (2015), pp. 911-919

[9] Y. Y. Wang, Z. Zhang and R. Yang, "Improvement of the Economic House of Quality in Service Industry Based on SE Coefficient and Its Applications", Science Research Management, vol. 33, no. 4, (2012), pp. 48-54.

[10] X. F. Xu and Z.J. Wang, "State of the Art: Business Service and Its Impacts on Manufacture", Journal of Intelligent Manufacturing, vol. 22, no. 5, (2011), pp. 653-662.

[11] Y. L. Wang, "Promotion of Service-oriented Manufacture: Strategic Thinking on Optimization of the Industrial Structure Adjustment in China", Journal of Xi'an Jiao Tong University (Social Science Edition), vol. 30, no. 2, (2010), pp. 26-31.

[12] G.Q. Chen, "Three-dimensional Business Process", Tsinghua Management Review, vol. 36, no. 6, (2011), pp. 77-84.

[13] C. Kowalkowski, L. Witell and A. Gustafsson, "Any Way Goes: Identifying Value Constellations for Service Infusion in SMEs", Industrial Marketing Management, vol. 42, no. 1, (2013), pp. 18-30.

[14] Y. Wei, D. B. Li and Y. F. Tong, "Customer Demand Oriented Fuzzy Cluster Analysis of Manufacturing Resource Service", Mechanical Engineering in China, vol. 22, no. 23, (2011), pp. 28282833.

[15] Q. Tang, G. S. Wang and L. J. Su, "Integrated Lotsizing and Scheduling for Multi-variety Batch Production by Turns in Chemical Industry", Control and Decision, Vol. 30, no. 2, (2015), pp. 289-295.

[16] B. H. Pang, "An Empirical Study of Symbiotic Evolutionary Model of Production Services and Manufacture in China", Management Science in China, vol. 27, no. 2, (2012), pp. 176-183.

[17] S. Z. Yu, J. Chen and X. T. Wang, "Final Priority Determining Method of Technical Characteristics Considering Competitive Analysis in House of Quality for Product Improvement", Computer Integrated Manufacturing Systems, vol. 18, no. 10, (2012), pp. 2245-2253.

[18] Z. M. Lin, "Shoe-shaped Gold Ingot Curve of Postmodern Management Era Exploration on Achieving Business Optimal Combination for the Enterprise", Management Scientist, vol. 5, no. 4, (2012), pp. 3-20.

[19] Y. 1. LI, J. M. Yao and M. H. Jiao, "Methodology for Determining the Final Importance Ratings of Engineering Characteristics in House of Quality Based on BSC", Journal of mechanical engineering, vol. 46, no. 4, (2010), pp. 177-185.

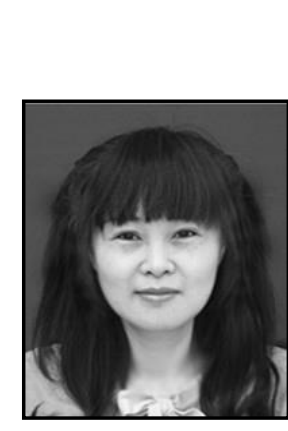

\section{Authors}

Qi Tang, she received $\mathrm{PhD}$ in system engineering from Northeastern University. She current research interests include production operation and management, optimization methods, etc.

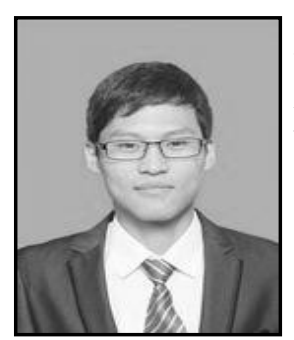

Guozhi Lin, he is a master graduate student of Shenyang University of Technology. He current research interests include production operation and Logistics management and Engineering, etc. 
International Journal of Multimedia and Ubiquitous Engineering

Vol. 12, No. 5 (2017) 